\title{
Vaccination with viral protein-mimicking peptides postpones mortality in domestic pigs infected by African swine fever virus
}

\author{
VADIM IVANOV $^{1}$, EVGENIY E. EFREMOV ${ }^{2}$, BORIS V. NOVIKOV ${ }^{3}$, VLADIMIR M. BALYSHEV ${ }^{3}$, \\ SODNOM Zh. TSIBANOV ${ }^{3}$, TATIANA KALINOVSKY ${ }^{1}$, DENIS V. KOLBASOV ${ }^{3}$, \\ ALEKSANDRA NIEDZWIECKI $^{1}$ and MATTHIAS RATH ${ }^{1}$ \\ ${ }^{1}$ Dr Rath Research Institute BV, Santa Clara, CA 95050, USA; ${ }^{2}$ Cardiology Research Center, 121552 Moscow; \\ ${ }^{3}$ National Research Institute for Veterinary Virology and Microbiology, 601120 Pokrov, Russia
}

Received November 26, 2010; Accepted March 2, 2011

DOI: $10.3892 / \mathrm{mmr} .2011 .454$

\begin{abstract}
Periodic outbreaks of African swine fever virus (ASFV) infection around the world threaten local populations of domestic pigs with lethal disease and provide grounds for pandemic spread. Effective vaccination may bring this threat under control. We investigated the effectiveness of select peptides mimicking viral proteins in establishing a protective immune response. Forty-six synthetic peptides based on the analysis of the complete nucleotide sequence of ASFV were tested for immunogenicity in mice. The 17 best immune response-inducing peptide candidates were selected for further investigation. Twenty-four domestic pigs, 3-4 months old and weighing $20-25 \mathrm{~kg}$, were divided into six groups $(\mathrm{n}=4)$ and immunized by subcutaneous injection using a standard threeround injection protocol with one of four peptide combinations prepared from the 17 peptides (Groups 1-4) or with carrier only (Group 5). Group 6, the control, was not vaccinated. Animal body temperature and behavior were monitored during and post immunization for health assessment. Two weeks after the last round of immunizations, the pigs were infected with live ASFV (Espania 70) at $6.0 \mathrm{Ig} \mathrm{GAE} 5 \mathrm{~cm}^{3}$, and the survival rate was monitored. Blood samples were collected for analysis the day before infection and on days 3, 7 and 10 post-infection, or from deceased animals. The serum titers of specific immunoglobulins against synthetic peptides and whole inactivated ASFV were determined by enzyme immunoassay before and after infection. The presence of viral DNA in blood serum samples was determined by polymerase chain reaction. Viral infection activity in blood sera was determined by heme absorption in cultured porcine bone marrow and porcine leukocyte cells. Repeating the injection of synthetic peptides in both the mice and pigs produced an immune response
\end{abstract}

Correspondence to: Dr Aleksandra Niedzwiecki, Dr Rath Research Institute BV, 1260 Memorex Drive, Santa Clara, CA 95050, USA E-mail: author@drrath.com

Key words: African swine fever infection, protein-mimicking peptides, vaccination, domestic pigs, mortality specific to individual peptides, which differed widely in the intensity scale. Specific anti-whole virus immunoglobulin binding activity in the swine serum samples from all groups was below the detection limit. Viral DNA was positively identified in all the samples infected with viral preparations. Viral infection activity was present in all the infected animals and steadily increased with time. On day 3 after infection, the viral titer was significantly lower in Groups 1 and 3 than in the unvaccinated controls. In deceased animals, the viral titer was significantly lower in Groups 1 and 3 than in the controls. All infected animals died within 17 days of infection. The average survival rate was significantly higher in Groups 1 and 3 (12.0 and 14.3 days, respectively) than in the controls (9.8 days). Vaccination with specific synthetic peptides significantly delayed mortality in domestic pigs infected with ASFV. These results justify further investigation aimed at developing an effective vaccine against ASFV infection.

\section{Introduction}

African swine fever (ASF), a tick-borne (1) highly contagious disease that has an almost $100 \%$ mortality rate in infected domesticated swine, was first reported in Kenya in 1921 (2). In the 1950s and 1960s, it became epidemic in many European and African countries, resulting in heavy economic losses in affected areas. The ASF virus (ASFV) originates from subSaharan Africa, where it naturally infects wart hogs and bush pigs without apparent symptoms. Presently, ASF is endemic in many Mediterranean and African countries, and remains one of the most serious viral diseases threatening the swine industry due to a lack of effective prophylactic measures (3-5). Since to date no preventive measures have been developed, the quarantine and slaughtering of infected animals is the routine method for preventing the spread of the disease.

ASFV mainly replicates in macrophages and monocytes, and induces a host immune response characterized by the lack of neutralizing antibodies (6-8). Acute infections are associated with decreased numbers of circulating macrophages, monocytes, lymphocytes and neutrophils (5). Disseminated intravascular coagulation develops during the late phase of acute infections, and this may lead to the characteristic hemorrhagic syndrome (9). A striking aspect of ASFV infection is 
that virus-specific antibodies - even those from recovered or chronically infected pigs, or those found in ASFV-resistant animal species inoculated with the virus - do not neutralize the virus $(3,6,7)$.

The causative agent of ASF is the only member of the family Asfarviridae; a large (200-nm diameter) icosohedral cytoplasmic DNA virus $175-215 \mu \mathrm{m}$ in diameter consisting of a double-stranded 170-kb long DNA genome which encodes 151 identified open reading frames (10). Viral proteins have been localized and studied by various research groups (11-18). Although it has been shown that ASFV does not induce neutralizing antibodies, different isolates of ASFV have been demonstrated to be neutralized by convalescent swine immune sera and monoclonal antibodies $(8,19,20)$. Gomez-Puertas et al demonstrated that certain neutralizing antibodies were capable of neutralizing different proteins of ASFV, inhibiting both virus attachment and internalization (21).

Our main objective was to develop novel peptides for a disease-protective vaccine against ASFV, and to observe whether the survival time of domestic pigs vaccinated with these peptides, then challenged with ASFV, would be increased.

\section{Materials and methods}

Peptide design. Forty-six synthetic peptides based on the analysis of the complete nucleotide sequence of ASFV (10) (Table I) were synthesized and biotynilated at the N-terminal using four carbon spacers by GenScript (Piscataway, NJ, USA).

Preparation of conjugate peptide and carrier protein. Conjugate streptavidin-polyHRP20, \#SP20C (Str-HRP), utilized as a carrier protein, was purchased from SDT (Germany); urea and salts for PBS were obtained from Fluka (Schweiz). Reagents were of analytical grade. Solutions were prepared using pyrogen-free milliQ grade water. Peptides were dissolved in $8 \mathrm{M}$ urea, mixed with Str-HRP solution in PBS and incubated at $+4^{\circ} \mathrm{C}$ overnight. The mixture of peptides and carrier protein (Str-HRP) was frozen and stored at $-20^{\circ} \mathrm{C}$ until use for the immunization of animals. The final concentrations of the peptide-Str-HRP solutions were 0.8 and $0.6 \mathrm{mg} /$ $\mathrm{ml}(0.3 \mathrm{mM})$ for peptides and Str-HRP, respectively. The final concentrations of urea in the peptide-Str-HRP solutions were $2 \mathrm{M}$ for all peptides.

Immunization of mice. Female BALB/C mice (five per peptide) were immunized by intraperitoneal injection using $100 \mu \mathrm{g}$ peptide per animal in a final volume of $250 \mu \mathrm{l}$ of 1:1 (v:v) of peptide + Str-HRP:adjuvant using complete Freund's adjuvant (Calbiochem, CA, USA) on day 0 and incomplete Freund's adjuvant (Calbiochem) on days 7, 14 and 28. Immunization caused a $3.33 \%$ mortality rate in mice without apparent preferences towards individual peptides. On the 45th day, the mice were sacrificed and blood was collected in 2-ml microcentrifuge tubes. Blood serum was prepared by centrifugation, aliquoted and stored at $-20^{\circ} \mathrm{C}$. All procedures were performed according to the humane and customary care and use of experimental animals, and followed a protocol approved by the internal institutional animal safety review committee.
Immunization of pigs. Twenty-four domestic pigs (Large White breed), 3-4 months old and weighing 20-25 kg, were obtained from a farm in Vladimir, Russia. The pigs were not vaccinated against any infectious disease. After a quarantine period, the experimental animals were divided into six groups (four gilts in each). Each group was immunized with one of four synthetic peptide group combinations (Table II) using the 17 peptides selected for high immune response from the murine experiment. The pigs were injected subcutaneously with $2.5 \mathrm{ml}$ of peptide/Str-HRP/adjuvant into the ear bases using complete Freund's adjuvant on day 0 and incomplete Freund's adjuvant on days 7 and 14. Blood samples were collected for serum preparation on day 14 prior to the second booster and on day 28 of the vaccination protocol. Animal body temperature and behavior were monitored during the immunization. Repeated injections of the synthetic peptides did not cause any health problems in the domestic pigs. The vaccinated animals did not exhibit any depression or refusal of forage intake during the immunization period. Animals in Group 5 received injections of carrier only and animals in Group 6 were not injected. All procedures were performed according to the humane and customary care and use of experimental animals, and followed a protocol approved by the internal institutional animal safety review committee.

Infection of pigs with ASFV. Two weeks after the last round of immunization, the pigs were challenged with a virulent ASF virus [strain Espania (E-70) intramuscularly at a dose of $\left.1,000 \mathrm{HAU}_{50}\right]$. ASF virus virulent strain E-70 with the infectious activity of $6.0 \mathrm{lg} \mathrm{HAU}_{50} / \mathrm{cm}^{3}$ was obtained in the form of virus-containing blood from Spain in 1978. ASFV was grown in Eagle's medium (MEM) with $10 \%$ of porcine blood serum, $\mathrm{pH}$ 7.2-7.4, in 1- or 2-day porcine bone marrow (PBM) cell cultures or porcine leukocyte (PL) cell cultures in plastic flasks.

Animal body temperature and survival of gilts was monitored daily throughout the study. Blood samples for analysis were collected a day before infection, and on days 3, 7 and 10 after infection, or from deceased animals. The serum titer of specific immunoglobulins against synthetic peptides and whole inactivated ASFV were determined by enzyme immunoassay (EIA) before and after infection.

Anti-peptide immune response assay. Microtiter plates were coated with individual peptides in $100 \mu \mathrm{l} / \mathrm{well} 5 \mu \mathrm{g} /$ $\mathrm{ml}$ peptide in $50 \mathrm{mM}$ carbonate buffer, $\mathrm{pH} 9.5$, for $20 \mathrm{~h}$ at $20^{\circ} \mathrm{C}$. After washing, the wells were incubated with serial dilutions of mouse serum in PBS/ $0.5 \%$ BSA $/ 0.05 \%$ Tween-20 (binding buffer; BB). After another washing step, the wells were incubated with $100 \mu \mathrm{l} /$ well rabbit anti-mouse $\mathrm{IgG}$ or rabbit anti-swine IgG (for mouse or pig samples, respectively) polyclonal antibodies conjugated with horse radish peroxidase (HRP) in $\mathrm{BB}$ for $30 \mathrm{~min}$ at $37^{\circ} \mathrm{C}$. After a final washing, the titer of anti-peptide mouse $\operatorname{IgG}$ was determined by color reaction with TMB substrate solution at $450 \mathrm{~nm}$. Titer results were corrected by adjustment to individual peptide binding to plastic wells, which was determined by the amount of plasticbound biotin as follows: individual peptide-covered wells were incubated with $100 \mu \mathrm{l} /$ well streptavidin-HRP solution in $\mathrm{BB}$ for $30 \mathrm{~min}$ at $37^{\circ} \mathrm{C}$. After washing, peptide binding was 
Table I. Synthetic peptides (PEPs).

Proteinase S273R

PEP1

PEP2

PEP3

PEP4

PEP5

Protein B438 (cell attachment sequence)

PEP6

PEP7

PEP8

PEP9

Protein p220 (precursor of structural proteins p158, p327, p34 and p14

PEP10

PEP11

PEP12

PEP13

PEP14

PEP15

PEP16

Protein p10 (structural protein/

DNA binding)

PEP17

P11.5 (structural protein)

PEP18

PEP19

PEP20

P12 (virus attachment)

PEP21

P14.5 (structural protein/DNA binding) PEP22

PEP23

PEP24

P17 (structural protein/

central transmembrane region) PEP25

P22 (structural protein incorporated into the membrane of infected cells)

PEP26

PEP27

P30 (inhibits virus internalization)

PEP28

PEP29

PEP30

P54 (inhibits virus binding/antigenic/ABs block viral attachment/induces apoptosis)

PEP31

PEP32

PEP33

P72 (major capsid protein/immunogenic/ used in diagnostic tests for ASFV/

monocl. ABs described)

PEP34

PEP35

PEP36
-S-E-C-A-E-H-L-T-N-K-D-S-C-L-S-K-K-I-

-L-E-K-K-E-T-L-G-C-D-S-E-S-C-V-

-Y-K-G-E-E-L-Q-Y-V-E-G-K-V-V-K-R-P-C-N-

-V-D-M-R-G-D-C-W-S-I-E-Y-

-I-R-H-Q-R-S-Q-T-E-C-G-

-N-E-Y-T-N-S-P-E-K-A-E-K-G-L-Q-L-S-D-L-R-N-

-T-E-N-L-I-R-R-N-V-V-R-T-E-K-K-T-

-P-K-D-S-Q-H-G-R-E-Y-Q-E-F-S-A-N-R-H-

-A-E-K-D-H-S-L-R-G-D-N-

-P-L-D-R-R-I-E-A-Q-R-L-D-R-K-H-I-

-Y-D-S-C-S-R-L-L-Q-I-I-D-F-Y-T-D-I-V-Q-K-K-Y-G-G-G-E-D-C-E-C-T-R-V-

-V-Q-K-K-Y-G-G-G-E-D-C-E-C-T-R-V-

-I-N-E-L-K-K-E-H-T-D-K-I-Q-I-V-S-K-L-

-P-K-G-Q-T-R-T-L-G-S-N-R-E-R-E-R-I-

-M-S-R-I-F-R-G-D-N-A-L-N-M-G-R-P-K-F-L-S-D-Q-I-F-N-K-V-

-S-R-I-F-R-G-D-N-

-S-R-L-T-K-S-E-L-E-K-K-I-K-R-S-K-

-T-K-L-D-Q-E-E-K-K-A-

-R-C-A-W-E-E-T-K-N-I-I-N-D-F-L-E-I-P-E-E-R-C-T-

-I-E-N-M-D-D-L-Q-K-G-

-P-R-Q-Q-K-K-C-S-K-A-E-E-C-T-C-N-N-G-S-C-S-

-L-K-E-D-S-R-D-R-T-

-M-E-K-I-A-E-E-D-I-

-N-K-P-E-D-D-E-E-S-G-A-K-P-K-K-K-H-

-F-R-K-R-K-N-S-T-S-L-Q-S-H-I-P-S-D-E-Q-L-

-V-C-K-V-D-K-D-C-G-S-G-E-H-C-V-

-S-C-L-D-A-V-K-M-D-K-R-N-I-K-I-D-S-K-I-S-S-C-E-

-F-E-E-E-T-E-S-S-A-S-S-E-S-

-F-E-Q-E-P-S-S-E-E-P-K-D-S-K-L-

-L-K-E-E-E-K-E-V-V-R-L-M-V-I-K-L-L-K-K-N-K-L-

-S-R-K-K-K-A-A-A-A-I-E-E-E-D-I-

-N-K-P-V-T-D-N-P-V-T-D-R-L-

-I-E-N-L-R-Q-R-N-T-Y-T-H-K-D-L-E-N-

-N-K-S-Y-G-K-P-D-P-E-P-T-

-Y-C-E-Y-P-G-E-R-L-Y-E-N-V-R-F-D-V-N-G-N-S-L-D-E-Y-S-S-D-V-T-T-L-

-L-C-N-I-H-D-L-H-K-P-H-Q-S-K-P-I-L-T-D-E-N-D-T-Q-R-T-C-S- 
Table I. Continued.

\begin{tabular}{|c|c|}
\hline PEP\# & Sequence of amino acids \\
\hline \multicolumn{2}{|c|}{$\begin{array}{l}\text { P72 (Major capsid protein/immunogenic/ } \\
\text { used in diagnostic tests for ASFV/ } \\
\text { monocl. ABs described) }\end{array}$} \\
\hline PEP37 & -Q-K-D-L-V-N-E-F-P-G-L-F-I-R-Q-S-R-F-I-P-G-R-P-S-R-R-N-I-R-F-K-P- \\
\hline PEP38 & -A-C-S-S-I-S-D-I-S-P-V-T-Y-P-I-T-L-P-I-I-K-N-I-S-V-T-A-H-G-I-N-L-I-D-K- \\
\hline PEP39 & -L-K-P-R-E-E-Y-Q-P-S- \\
\hline \multicolumn{2}{|c|}{ Proliferating antigenic protein } \\
\hline PEP40 & -P-K-K-R-V-V-P-N-F-E-R-K-G- \\
\hline PEP41 & -S-E-P-E-L-D-M-D-L-I-E-M-E-K-S-I-S-E-E-R-L-K-N- \\
\hline \multicolumn{2}{|c|}{ Serine proteinase inhibitor } \\
\hline PEP42 & -F-E-E-D-K-K-M-L-E-L-F-V-Q-K-L- \\
\hline PEP43 & -F-K-Y-P-E-I-E-K-Y-E-V-D- G- \\
\hline PEP44 & -F-E-D-L-N-F-K-Y-L-Y-N-S-D-K-N-S-Q-H-D-K-D-F- \\
\hline PEP45 & -I-K-K-Q-I-P-R-C-K-D-A-F-N-K-I-E-S- \\
\hline PEP46 & -V-K-H-V-E-K-K-L-D-M-L-D-R- \\
\hline
\end{tabular}

Table II. ASFV infection protocol: peptide (PEP) combinations for pig immunization.

\begin{tabular}{lccr}
\hline Combination 1 & Combination 2 & Combination 3 & Combination 4 \\
\hline PEP11 & PEP4 & PEP30 & PEP31 \\
PEP14 & PEP5 & PEP35 & PEP32 \\
PEP15 & PEP26 & PEP36 & PEP37 \\
PEP16 & PEP45 & PEP38 \\
PEP19 & & PEP39 \\
\hline
\end{tabular}

determined by color reaction with TMB substrate solution at $450 \mathrm{~nm}$. Test procedures were performed in triplicate for each serum sample. The resulting anti-peptide titer was expressed as an average from animals in corresponding groups $(n=5$ in mouse experiment, $n=4$ in pig experiment) in arbitrary units.

Isolation of ASF virus. Isolation of the ASF virus from the blood of the challenged controls was carried out in PBM cell culture, and its genome was identified by PCR. Viral infectious activity in the blood of infected pigs was determined by titration in PBM or PL cell cultures. The readings were based on heme adsorption (HAd) test results. The virus titers were determined from the results of two titrations and calculated using the Reed-Muench method.

Isolation of nucleic acids. Nucleic acids were isolated from the blood of the infected pigs after challenge using ASFV DNA detection by PCR. For this purpose, $100 \mu \mathrm{l}$ of blood was lysed in $500 \mu \mathrm{l}$ of chaotropic lysing buffer at $65^{\circ} \mathrm{C}$. After lysis, $30 \mu \mathrm{l}$ of a sorbent was added and the solution was carefully mixed and centrifugated at 12,000 rpm. The supernatant was removed, the sediment was washed in $600 \mu \mathrm{l}$ of $70 \%$ ethanol and the tubes were centrifugated at 12,000 rpm. The supernatant was removed and the sediment was dried at $56^{\circ} \mathrm{C}$. DNA was eluated in $50 \mu \mathrm{l}$ of TE-buffer. PCR was conducted in a reaction mixture at a volume of $25 \mu \mathrm{l}$ containing the 5-fold buffer for amplification, $100 \mu \mathrm{M}$ of each dNTP, 5 pmol of each primer (p72F, 5'-tgt gcg cgg atc ctg cat ccc agg gga taa aat g-3' and p72R, 5'-aaa att ctc cgg act aat cet ttt gcg atg caa gct-3'), 1 unit of Taq-DNA-polymerase and $5 \mu \mathrm{l}$ of the DNA preparation. The results were read using electrophoretic separation indices of the amplification products on $1.5 \%$ agarose gel prepared in Tris borate buffer.

Statistical analysis. Data are expressed as the means \pm SD, as indicated in the results, for the groups. Data from the two control groups (Groups 5 and 6) that were not immunized with synthetic peptides were combined for calculations as a single control group. Data were analyzed by the independent sample t-test, using MedCalc Software (Markakerke, Belgium). Pearson's correlation coefficient was determined for the correlation between the mouse and pig immunogenic responses to the 17 selected peptides using MedCalc Software (Markakerke).

\section{Results}

Effect of synthetic peptide injection on immune response in mice and pigs. Repeated injections of synthetic peptides in both mice and pigs produced an immune response specific to 
Table III. Immune response against individual peptides in mice.

\begin{tabular}{|c|c|c|}
\hline Peptide (PEP) & AB Titer & Rank \\
\hline PEP1 & 8.82 & 33 \\
\hline PEP2 & 4.70 & 38 \\
\hline PEP3 & 16.98 & 25 \\
\hline PEP4 & 160.52 & 7 \\
\hline PEP5 & 418.99 & 4 \\
\hline PEP6 & 17.04 & 24 \\
\hline PEP7 & 25.67 & 21 \\
\hline PEP8 & 5.21 & 36 \\
\hline PEP9 & 1.54 & 41 \\
\hline PEP10 & 9.88 & 32 \\
\hline PEP11 & 88.89 & 9 \\
\hline PEP12 & 24.04 & 22 \\
\hline PEP13 & 1.92 & 40 \\
\hline PEP14 & 33.74 & 16 \\
\hline PEP15 & 979.92 & 1 \\
\hline PEP16 & 68.42 & 10 \\
\hline PEP17 & 0.77 & 44 \\
\hline PEP18 & 0.47 & 45 \\
\hline PEP19 & 597.87 & 2 \\
\hline PEP20 & 7.45 & 34 \\
\hline PEP21 & 30.57 & 17 \\
\hline PEP22 & 4.17 & 39 \\
\hline PEP23 & 14.05 & 29 \\
\hline PEP24 & 1.08 & 43 \\
\hline PEP25 & 446.59 & 3 \\
\hline PEP26 & 60.47 & 12 \\
\hline PEP27 & 39.14 & 14 \\
\hline PEP28 & 0.04 & 46 \\
\hline PEP29 & 1.53 & 42 \\
\hline PEP30 & 220.59 & 5 \\
\hline PEP31 & 199.08 & 6 \\
\hline PEP32 & 27.09 & 20 \\
\hline PEP33 & 5.15 & 37 \\
\hline PEP34 & 38.42 & 15 \\
\hline PEP35 & 9.97 & 31 \\
\hline PEP36 & 58.88 & 13 \\
\hline PEP37 & 15.17 & 26 \\
\hline PEP38 & 13.93 & 30 \\
\hline PEP39 & 64.67 & 11 \\
\hline PEP40 & 15.06 & 27 \\
\hline PEP41 & 14.15 & 28 \\
\hline PEP42 & 19.98 & 23 \\
\hline PEP43 & 29.97 & 18 \\
\hline PEP44 & 7.11 & 35 \\
\hline PEP45 & 125.12 & 8 \\
\hline PEP46 & 27.22 & 19 \\
\hline
\end{tabular}

the individual peptides (Table III, immune response against individual peptides in mice; Table IV, domestic pig data). The intensity of the immune response varied from peptide
Table IV. Immune response against individual peptides (PEP) in domestic pigs.

\begin{tabular}{lcr}
\hline Combination & Adjusted titer & Rank \\
\hline Combination 1 & & \\
PEP11 & 2.899 & 4 \\
PEP14 & 1.703 & 7 \\
PEP15 & 7.301 & 1 \\
PEP16 & 0.709 & 9 \\
PEP19 & 1.832 & 6 \\
Combination 2 & & \\
PEP4 & 0.288 & 13 \\
PEP5 & 0.418 & 11 \\
PEP25 & 3.254 & 3 \\
PEP45 & 0.863 & 8 \\
Combination 3 & & 14 \\
PEP30 & 0.288 & 10 \\
PEP35 & 0.432 & 12 \\
PEP36 & 0.398 & 17 \\
PEP37 & 0.030 & 15 \\
PEP38 & 0.192 & 2 \\
PEP39 & 4.040 & 5 \\
Combination 4 & & \\
PEP31 & 2.129 & \\
PEP32 & 0.100 & \\
\hline
\end{tabular}

to peptide. The 17 peptides with the most intensive immune response in mice were selected for further testing in the domestic pig model. The intensity of immune response was positively correlated $(\mathrm{r}=0.693, \mathrm{p}=0.002)$ when compared between mice and pigs for the 17 peptides tested in both species. Specific anti-whole virus immunoglobulin binding activity in swine serum samples was below the detection limit in all animals (tested only in pigs).

Effect of synthetic peptide injections on viral infection activity in pigs. Viral DNA was positively identified in all the animal samples infected with the viral preparation. Viral infection activity was present in all the infected animals and steadily increased with time, as shown in Fig. 2. On day 3 after infection, viral titers in the animals in Groups 1 and 3, vaccinated with peptide Combinations 1 and 3, respectively, were significantly lower $(14 \%, \mathrm{p}=0.012$ and $\mathrm{p}=0.038)$ than in the controls (Groups 5 and 6). Among the deceased animals, the viral titers in Groups 1 and 3 were significantly lower $(6 \%, \mathrm{p}=0.031$ and $7 \%, \mathrm{p}=0.017$, respectively) than in the controls. Virus accumulation in animal blood on day 3 following the infection was found to be 3.0-4.75 $\mathrm{lg} \mathrm{HAU}_{50} / \mathrm{cm}^{3}$. For deceased animals, the virus titers reached 5.0-6.5 $\mathrm{lg} \mathrm{HAU}_{50} / \mathrm{cm}^{3}$.

Results of virus challenge inoculation in pigs. The infected animals were observed daily for body temperature increases and other symptoms of infection. From day 3 after viral challenge, the gilts exhibited an increase in body temperature that reached $41.0-42.0^{\circ} \mathrm{C}$. Changes in body temperature monitored in animals before and after infection did not differ between 


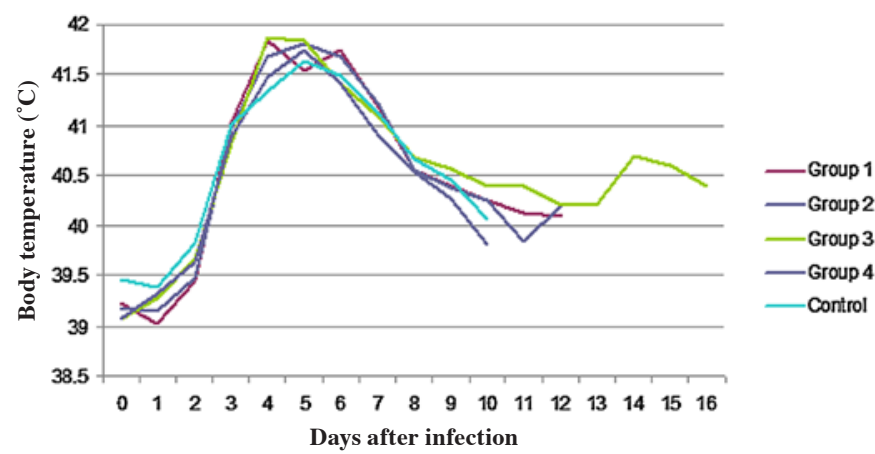

Figure 1. Infection of domestic pigs with ASFV: body temperature changes.

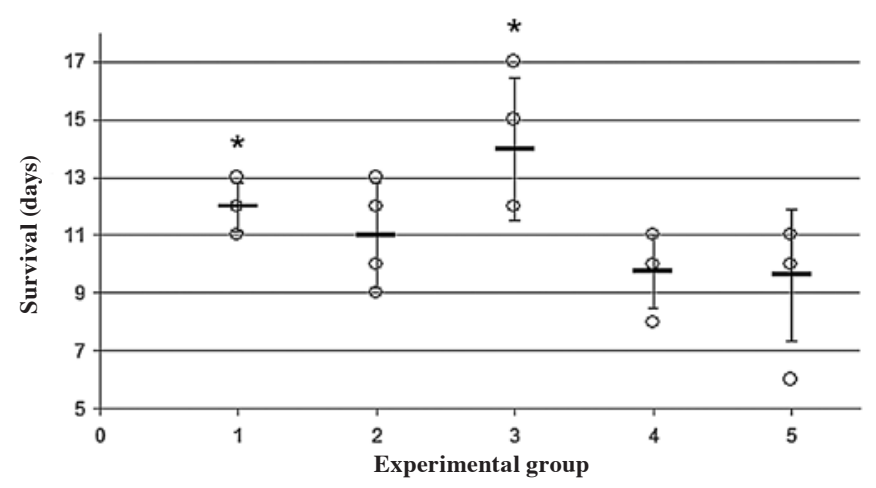

Figure 2. Infection of domestic pigs with ASFV: survival rate. ${ }^{*} \mathrm{P}<0.05$, significant difference compared to the control (Groups 5 and 6).

groups (Fig. 1). The disease took its course, demonstrating specific ASF manifestations in both vaccinated pigs and controls, including marked depression, refusal of forage intake, diarrhea (containing blood inclusions), as well as cutaneous cyanosis in such areas as the ears, neck, perineum and abdominal wall.

Survival of infected animals. All infected animals died within 17 days of infection. The mean survival rates of the animals in Groups 1 and 3 were significantly higher $(\mathrm{p}=0.038$ and $\mathrm{p}=0.030$, respectively) than in the controls, as shown in Fig. 2 . The average survival of Group 1 animals was $12.0 \pm 0.82$ days, and that of Group 3 animals $14.3 \pm 2.63$ days, in contrast to an average survival of $9.8 \pm 2.38$ days for the control animals (combined Groups 5 and 6). The mean viral titer was significantly lower in Group 1 (in deceased animals) and Group 3 (at day 3 after infection and in deceased animals) compared to the non-immunized controls.

\section{Discussion}

Due to the inability to vaccinate against ASFV, researchers have turned to studying viral proteins in ASFV and using peptide isolates for vaccination attempts against ASFV. Carracosa et al (11) localized seven ASFV structural proteins in the virion by immunoelectron microscopy: proteins p14 and p24 in the external region of the virion, proteins p12, $\mathrm{p} 72, \mathrm{p} 17$ and $\mathrm{p} 37$ in the intermediate layers, and protein p150 in the nucleoid and in one vertex. In addition, a monoclonal antibody that recognized protein p150 as well as p220, a virus-

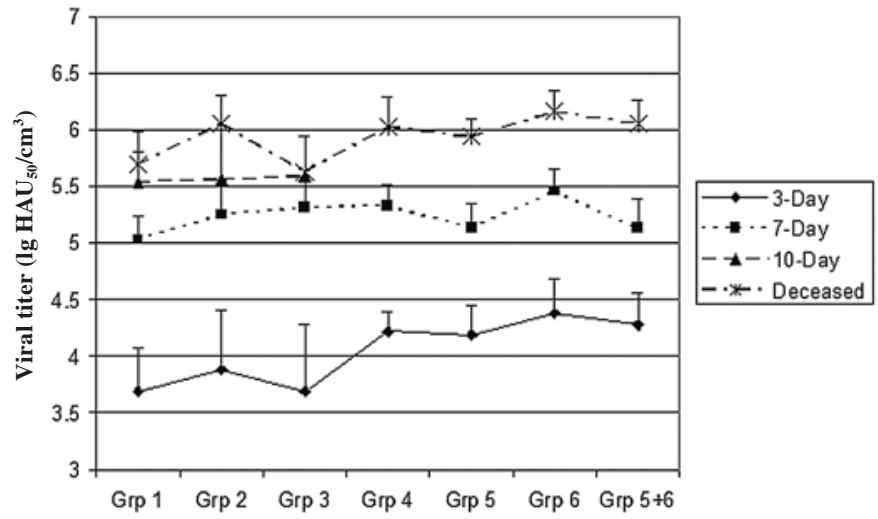

Figure 3. Infection of domestic pigs with ASFV: viral titer. " $\mathrm{P}<0.05$, significant difference compared to the control (Groups 5 and 6).

induced, non-structural protein, was also capable of binding to a component present in the nucleus of both uninfected and virus-infected cells. Lopez-Otin et al mapped and sequenced the gene coding protein $\mathrm{p} 72$, the major capsid protein of ASFV and the most immunogenic protein in natural infection (12). Galindo et al characterized the ASFV protein p49 (open reading frame $\mathrm{B} 438 \mathrm{~L}$ ), a structural component of purified virus particles, which is transcribed late during viral infection and located in cytoplasmic virus factories (13).

Gomez-Puertas et al studied the induction of neutralizing antibody during ASFV infection in pigs using attenuated viruses (21). Of the surviving pigs inoculated with three different isolates, the group inoculated with E75CV1-4 presented detectable viremia for at least 3 weeks, while pigs inoculated with isolates 1207VR15 and 608VR13 showed neither viremia nor clinical symptoms. Convalescent swine sera obtained 3-4 weeks after infection demonstrated a reduction of infectivity of $87-100 \%$. Western blot (immunoblot) analysis of sera from convalescent pigs revealed that p72, p30 and p54 were three of the most antigenic proteins during infection (21), confirming previous reports (14-18). The ASFV neutralization proteins anti-p72 and -p54 in the sera of convalescent pigs neutralized the virus only before attachment to different susceptible cells, whereas serum against p30 neutralized the virus equally when antibodies were incubated with the virus before or after attachment to cells (21). Sera against p72 and p54 inhibited $~ 60 \%$ of virus attachment in both Vero cells and pig macrophages, while anti-p30 serum did not inhibit virus attachment to cells. Inhibition of virus internalization showed that more than $90 \%$ of the virus incubated post attachment with anti-p72 or -p54 was internalized into the cells after $4 \mathrm{~h}$ of incubation at $37^{\circ} \mathrm{C}$. However, anti-p30 antibodies inhibited virus internalization by more than $95 \%$ in both Vero cells and pig macrophages. The authors concluded that antibodies against p72 and p54 were capable of inhibiting an early step in the virus replication cycle related to virus attachment, while anti-p30 antibodies inhibited a later step related to virus internalization (21). These results indicate that specific proteins can be assigned to different neutralization mechanisms. A previous study by Neilan et al evaluated the roles of p30, p54, p72 and p22 in protective immunity against ASFV by immunizing pigs with isolates of these proteins and challenging them with ASFV virus (22). Test animals exhib- 
ited a 2-day delay in the onset of clinical disease and reduced viremia levels at 2 days post-infection; however, by day 4 post-infection, there were no significant differences between the two groups, and all animals in both groups died between 7 and 10 days post-infection, indicating that neutralizing antibodies against these ASFV proteins were not sufficient for antibody-mediated protection.

Based on the functions of various proteins in ASFV, we synthesized peptide groups that mimicked these proteins, tested them for immune response individually, and selected the most responsive peptides. These 17 most responsive peptides were combined into four combinations for a vaccination study against ASFV in pigs. Combination 1 addressed the proteins p220, a precursor of structural proteins p158, p327, p14 and p11.5, a structural protein. Combination 2 targeted the proteinase S273R and p22, a structural protein incorporated into the membrane of infected cells, and a serine proteinase inhibitor. Combination 3 comprised peptides mimicking p30, a peptide that inhibits virus internalization, and p72, a major ASFV capsid protein. Group 4 targeted p54, an inhibitor of virus binding.

The results of this study indicated that the vaccination of pigs with the different synthetic peptide combinations resulted in a significantly increased average survival in the animals administered Combination 3 (Group 3) and Combination 1 (Group 1) over the control group. Group 3 animals showed an average increase in survival survival time of approximately 4 days compared to the control group, and of 2 days compared to the Group 1 animals. Combinations 2 and 4 did not significantly increase survival time in the ASFV challenged pigs. Of interest, p72, which acts at the first step of viral attachment and replication, and p30, which acts at the second step to inhibit viral internalization, were represented as synthetic peptides in Combination 3 - the combination most successful in increasing survival.

These findings, that vaccination with synthetic peptides increased survival by even 4 days, have significant practical applications. Potentially, with further reaserch, survival may be prolonged to weeks post-infection. Increased survival provides a partial solution to reducing the enormous practical problems associated with the need for rapid (within 1-3 days) termination (by cremation) of complete animal populations of infected pigs in all regional farms, in accordance with internationally accepted requirements.

In conclusion, vaccination with specific synthetic peptides significantly delayed mortality in domestic pigs infected with ASFV. These results confirm the usefulness of designing and studying synthetic peptides to develop effective vaccines against ASFV infection.

\section{Acknowledgements}

This study was funded by the Dr. Rath Health Foundation, a non-profit organization.

\section{References}

1. Kleiboeker SB and Scoles GA: Pathogenesis of African swine fever virus in Ornithodoros ticks. Animal Health Research Reviews 2: 121-128, 2001.
2. Montgomery RE: On a form of swine fever occurring in British East Africa (Kenya Colony). J Comp Path 84: 159-191; 243-262, 1921.

3. Costa JV: African swine fever virus. In: Molecular Biology of Iridoviruses. Darai G (ed). Kluwer Academic Publishers, Boston, Mass, pp247-270, 1990.

4. Viňuela E: African swine fever virus. Curr Top Microbiol Immunol 116: 151-170, 1985.

5. Wilkinson PJ: African swine fever virus. In: Virus Infections of Porcines. Pensaert MB (ed). Elsevier Sciences Publishers, B.V., Amsterdam, Holland, pp17-37, 1989.

6. DeBoer CJ: Studies to determine neutralizing antibody in sera from animals recovered from African swine fever and laboratory animals inoculated with Africa virus with adjuvants. Arch Gessante Virusforsch 20: 164-179, 1967.

7. De Boer CJ, Hess WR and Dardirl AH: Studies to determine the presence of neutralizing antibodies in sera and kidneys from swine recovered from African swine fever. Arch Virusforsch 27 44-54, 1969.

8. Ruiz-Gonzolvo F, Caballero C, Martinez J and Carnero ME: Neutralization of African swine fever virus by sera from African swine fever-resistant pigs. Am J Vet Res 47: 1858-1862, 1986.

9. Villeda C, Williams SM, Wilkinson PJ and Viňuela E: Haemostatic abnormalities in African swine fever, a comparison of two virus strains of different virulence (Dominican Republic '78 and Malta '78). Arch Virol 130: 71-83, 1993.

10. Yaňez RJ, Rodriguez JM, Nogal ML, Yuste L, Enriquez C, Rodriguez JF and Viňuela E: Analysis of the complete nucleotide sequence of African swine fever virus. Virology 208: 249-278, 1995.

11. Carracosa JL, Gonzalez AL, Carracosa BG, Enjuanes L and Viňuela E: Localization of structural proteins in African swine fever virus particlw by immunoelectron microscopy. J Virol 58: 377-384, 1986

12. López-Otin C, Freije JM, Parra F, Mèndez E and Viňuela E: Mapping and sequence of the gene coding for protein p72, the major capsid protein of African swine fever virus. Virology 175: 477-484, 1990

13. Galindo I, Viňuela E and Carrascosa AL: Characterization of the African swine fever virus protein p49: a new late structural polypeptide. J Gen Virol 81: 59-65, 2000.

14. Alonso C, Alcaraz C, Brun A, Sussman MD, Onisk DV, Escribano JM and Rock DL: Characterization of P30, a highly antigenic membrane and secreted protein of African swine fever virus. Virology 189: 368-373, 1992.

15. Alcaraz C, De Diego M, Pastor MJ and Escribano JM: Comparison of a radioimmunoprecipitation assay to immunoblotting and ELISA for detection of antibody to African swine fever virus. J Vet Diagn Invest 2: 191-196, 1990.

16. Alcaraz C, Rodriguez F, Oviedo JM, Eiras A, De Diego M, Alonso $\mathrm{C}$ and Escribano JM: Highly specific confirmatory Western blot test for African swine fever virus antibody detection using the recombinant virus protein $\mathrm{p} 54$. J Virol Methods 52: 111-119, 1995.

17. Rodrıguez F, Alcaraz C, Eiras A, Yaňez RJ, Rodrıguez JMC, Alonso C, Rodriguez JF and Escribano JM: Characterization and molecular basis of heterogeneity of the African swine fever virus envelope protein p54. J Virol 68: 7244-7252, 1994.

18. Rodriguez F, Ley V, Gomez-Puertas P, Garcia R, Rodriguez JF and Escribano JM: The structural protein p54 is essential for African swine fever virus viability. Virus Res 40: 161-167, 1996.

19. Ruiz-Gonzolvo F, Carnero ME, Caballero C and Martinez J: Inhibition of African swine fever infection in the presence of immune sera in vivo and in vitro. Am J Vet Res 47: 1249-1252, 1986.

20. Zsak L, Onisk DV, Alfonso DL and Rock DL: Virulent African swine fever virus isolates are neutralized by swine immune serum and by monoclonal antibodies recognizing a 72-kDa viral protein. Virology 196: 596-602, 1993.

21. Gomez-Puertas P, Rodriguez F, Oveida JM, Ramiro-Ibanez F, Ruiz Gonzalvo F, Alonso C and Escribiano JM: Neutralizing antibodies to different proteins of African swine fever virus inhibit both virus attachment and internalization. J Virol 70: 5689-5694, 1996

22. Neilan JG, Zsak L, Lu Z, Burrage TG, Kutish GF and Rock DL: Neutralizing antibodies to African swine fever virus proteins p30, p54 and p72 are not sufficient for antibody-mediated protection. Virology 319: 337-342, 2004. 